\title{
Targeted Deletion of CASK-Interacting Nucleosome Assembly Protein Causes Higher Locomotor and Exploratory Activities
}

\author{
Wen-Chuan Chung ${ }^{a, b}$ Tzyy-Nan Huang ${ }^{b}$ Yi-Ping Hsueh ${ }^{a, b}$ \\ ${ }^{a}$ Graduate Institute of Life Sciences, National Defense Medical Center, and ${ }^{b}$ Institute of Molecular Biology, \\ Academia Sinica, Taipei, Taiwan, ROC
}

\author{
Key Words \\ Cognitive impairment $\cdot$ Exploration - Locomotion • \\ $\mathrm{N}$-methyl-D-aspartic acid receptor subunit $2 \mathrm{~b}$. \\ Nucleosome assembly protein
}

\begin{abstract}
CASK-interacting nucleosome assembly protein (CINAP) has been shown to interact with the calcium/calmodulin-dependent serine kinase (CASK) and the T-box transcription factor T-brain-1 (Tbr1) thus modulating the expression of N-methyl-D-aspartic acid receptor subunit 2b (NMDAR2b) in cultured hippocampal neurons. To explore the physiological significance of CINAP in vivo, CINAP knockout mice were generated and subjected to biochemical, anatomical, and behavioral analyses. Unexpectedly, CINAP deletion did not impact NMDAR2b expression, and these CINAP knockout mice were consistently comparable to wild-type littermates in terms of immediate memory (assessed with the $Y$ maze) and associative memory (evaluated by conditioned taste aversion and contextual and auditory fear conditioning). Although CINAP deletion did not obviously influence learning and memory behaviors, CINAP knockout mice exhibited higher locomotor and exploratory activities. Compared with wild-type littermates, the horizontal and vertical movements of the CINAP knockout mice were higher in a novel environment; in home cages, rearing, sniffing, and jumping also occurred more frequently in CINAP knockout mice.
\end{abstract}

These observations suggest that although CINAP deletion in mice does not influence learning and memory behaviors, CINAP is required for restriction of locomotor and exploratory activities.

Copyright $\odot 2011$ S. Karger AG, Basel

\section{Introduction}

$\mathrm{X}$-linked mental retardation is a common and genetically heterogeneous disorder; the calcium/calmodulindependent serine protein kinase (CASK) was recently identified as a causative agent of X-linked mental retardation [1-4]. In addition to cognitive impairment, mutations in human CASK result in brain malformation and even lethality [4], while in mice, targeted deletion of CASK leads to lethality 1-2 days after birth [5]. Taken together, these genetic analyses highlight the importance of CASK in brain development and function [6].

CASK was originally identified as a multidomain scaffold protein that is widely distributed among subcellular compartments of neurons and interacts with a variety of cellular proteins. It therefore participates in several distinct processes, including synapse formation, synaptic targeting of ion channels, and transcriptional regulation $[6,7]$. In the nuclei of neurons, CASK interacts with at least three nuclear proteins: T-box transcription factor Tbrain-1 (Tbr1) [8], CASK-interacting nucleosome assem-

\section{KARGER \\ Fax +4161306 1234 \\ E-Mail karger@karger.ch}

www.karger.com (c) 2011 S. Karger AG, Basel

1424-862X/11/0193-0128\$38.00/0

Accessible online at:

www.karger.com/nsg
Dr. Yi-Ping Hsueh

Institute of Molecular Biology, Academia Sinica

128, Academia Rd., Section 2

Taipei 115, Taiwan (ROC)

Tel. +8862278 99311, E-Mail yph@gate.sinica.edu.tw 
bly protein (CINAP) [9], and the zinc finger transcription factor B cell lymphoma 11A (Bcl11A) [10]. Both Tbrl and Bcl11A recognize specific DNA sequences and bind to chromosomal DNA. CINAP, also known as differentially expressed nucleolar TGF- $\beta 1$ target (DENTT) [11], cell division autoantigen 1 nucleolar protein (CDA1) [12], or testis-specific Y-encoded-like protein 2 (TSPYL2), is involved in the regulation of nucleosome assembly [9]. Tbrl and CINAP interact with CASK [9] to form a complex that modulates gene expression of N-methyl-D-aspartate receptor subunit 2b (NMDAR2b) [9, 13]. Deletion of Tbr1 or knockdown of CINAP expression in neurons reduces the protein levels of NMDAR2b $[9,13]$. The CASK-Bcl11A complex regulates axon branching and outgrowth [10]; unlike Tbrl, thus far there is no evidence that CINAP forms a complex with Bcl11A [10].

Since CASK acts as a scaffold protein and interacts with many neuronal proteins $[6,7]$, we wished to investigate the physiological roles of individual CASK-binding partners in order to dissect the molecular functions of CASK in brain development and function. Given that the CINAP-CASK-Tbrl complex modulates NMDAR2b expression in cultured hippocampal neurons [9], and that NMDAR is critical for learning and memory, we suspected that the CINAP-CASK-Tbrl complex may be relevant to the mental retardation phenotype in patients carrying a CASK mutation. In this report, we generated CINAPdeleted mice to explore the physiological significance of CINAP. Although we unexpectedly found that CINAP deletion had no obvious effect on memory, the CINAP knockout mice exhibited higher locomotor and exploratory activities than their wild-type littermates, suggesting a role for CINAP in cognition, although CINAP may not be critical for learning and memory.

\section{Materials and Methods}

\section{CINAP Knockout Mice}

To construct the CINAP targeting vector, a genomic fragment containing the CINAP locus was first subcloned from a bacterial artificial chromosome clone (RP23-382J5) into a modified pBluescript vector containing a thymidine kinase cassette, a negative selection marker in embryonic stem (ES) cells, by a recombineering-based method [14]. The first loxP site and an EcoRI site were inserted in front of the CINAP translational start codon. The second loxP site and the flippase recognition site (FRT)-flanked Neo cassette, the positive selection marker for gene targeting in ES cells, were introduced into the first intron. The CINAP targeting vector was delivered into $\mathrm{C} 57 \mathrm{BL} / 6$ ES cells for production of chimeric mice that were crossed to C57BL/6-C2J albino strains; germline transmission was screened by coat color and genomic PCR with the primer pair 5'-TCAAGTGTGACTGGTGGCTAC- $3^{\prime}$ and 5'-CTATCTGTTGCTCCGTTTATGG-3'. To generate $\mathrm{CINAP}^{+/-}$female mice, $\mathrm{CINAP}^{+/ \text {targ }}$ female mice were bred to male E2A-Cre mice [15]. The $\mathrm{CINAP}^{+/-}$females were then crossed to wild-type C57BL/6 males to generate CINAP knockout male mice $\left(\mathrm{CINAP}^{-/ y}\right)$ and wild-type male littermates $\left(\mathrm{CIANP}^{+/ y}\right)$ for experimentation. Genotyping was carried out by genomic Southern blotting with the DNA fragments containing nucleotide residues $16,995-17,643$ and 29,047-29,594 of clone RP23-382J5 as the $5^{\prime}$ and $3^{\prime}$ probes, respectively.

\section{Antibodies}

Three regions of the CINAP protein, amino acid residues 1-208, 392-677, and 612-277, were fused to glutathione S-transferase and expressed in the bacterial strain BL21 codon(+). CINAP-1-208 was used as an immunogen to produce rabbit polyclonal antibodies. The CINAP-392-677 and 612-677 fusions were used to immunize mice. B cell hybridoma $2 \mathrm{G} 9$ was generated from a mouse immunized with CINAP-612-677 fusion proteins. Rabbit anti-NMDAR2B was purchased from Chemicon. Mouse monoclonal antibodies against $\beta$-tubulin and $\beta$-actin were obtained from Sigma.

\section{Histology and Immunostaining}

Mice 12-15 weeks old were anesthetized with a 4:1 mixture of $40 \mathrm{mg} / \mathrm{ml}$ ketamine and $16 \mathrm{mg} / \mathrm{ml}$ xylazine and perfused with 30 $\mathrm{ml}$ of cold phosphate-buffered saline followed by $30 \mathrm{ml}$ of $4 \%$ paraformaldehyde in phosphate-buffered saline. After postfixation in $4 \%$ paraformaldehyde overnight at $4{ }^{\circ} \mathrm{C}, 50$ - $\mu \mathrm{m}$-thick coronal sections were collected using a Vibratome. For examination of brain anatomy, coronal sections were stained following a protocol combining Luxol fast blue and Nissl staining. For immunoflourescence staining using CINAP 2G9 antibody, brain sections were incubated with $10 \mu \mathrm{g} / \mathrm{ml} 2 \mathrm{G} 9$ for $48 \mathrm{~h}$ at $4^{\circ} \mathrm{C}$, followed by application of the Tyramide Signal Amplification kit (PerkinElmer).

\section{Animals and Behavioral Analyses}

All animal experiments were carried out with the approval of the Academia Sinica Institutional Animal Care \& Utilization Committee in strict accordance with its guidelines and those of the Council of Agriculture Guidebook for the Care and Use of Laboratory Animals. Animals were housed in the animal facility of the Institute of Molecular Biology, Academia Sinica, under controlled temperature and humidity.

Fear Conditioning. One day before training (D-1), mice were pretrained in a habituation chamber (box B, $15 \times 15 \times 20 \mathrm{~cm}$ ) to habituate operator and equipment. On the training day (D0), mice were first placed in the conditional chamber (box A, $15 \times 15 \times$ $20 \mathrm{~cm}$ ) for a 4-min habituation, and then presented with three tone-shock pairings, which were three repeats of a tone (conditioned stimulus, CS; $18 \mathrm{~s}, 2 \mathrm{kHz}, 80 \mathrm{~dB}$ ) followed by an electronic foot shock (unconditioned stimulus, US; 0.6-0.7 mA, $2 \mathrm{~s}$ ) with a 1-min intertrial interval. After training, mice were returned to their home cages. At day 1 (D1), mice were put back in the conditional chamber (box A) in the absence of tones and foot shocks for $10 \mathrm{~min}$ to measure the freezing responses to a contextual environment (contextual fear conditioning). The average freezing percentage of the first $3 \mathrm{~min}$ indicated the degree of contextual memory. On day 2 (D2), mice were placed in box B and received 20 tones $(20 \mathrm{~s}, 2 \mathrm{kHz}, 80 \mathrm{~dB})$ with 5 -second intertrial intervals to 
measure the freezing response to auditory stimulation. The freezing percentages responding to the first four tones were averaged to reflect auditory fear conditioning. Freezing behaviors were measured using the FreezeScan ${ }^{\mathrm{TM}} 2.0$ system (CleverSys Inc.).

Conditioned Taste Aversion (CTA). During pretraining days, mice were deprived of water in their home cages and received their daily water for $15 \mathrm{~min}$ in the experimental cages. On conditioning day (D0), mice received $100 \mathrm{~mm}$ sucrose as an unfamiliar taste for $15 \mathrm{~min}$, and then were injected intraperitoneally with $\mathrm{LiCl}(0.15 \mathrm{M}, 20 \mu \mathrm{l} / \mathrm{g}$ of body weight). Mice were returned to their home cages and monitored for diarrhea. Mice were tested simultaneously every other day in the experiment cages with two drinking bottles containing $100 \mathrm{~mm}$ sucrose and water for $15 \mathrm{~min}$. Memory of the CTA was determined by the sucrose preference, which is reported as the percentage of the volume of consumed sucrose of the total consumed liquid (volume of consumed sucrose plus volume of consumed water).

Home Cage Behavior. Mice were habituated in individual cages at least 2 days before recording by a camera set in front of the home cage. During the experiment, food and water were provided ad libitum. Infrared-ray light-emitting diodes illuminated the behavior room for recording during the dark cycle. The recording time was from 13:00 to 12:00 for a total of $23 \mathrm{~h}$. The videos were then analyzed for mouse behaviors using the HomeCageScan system (CleverSys Inc.).

Open Field Test. Locomotion and exploratory behaviors were measured in a new environment (transparent plastic box $40 \times 40$ $\times 30 \mathrm{~cm}$ ). The area of the central region was equal to the total area of the four corners, and the regions were marked on the bottom of the box. Each mouse was placed individually in the center of the box, and its movement distance was recorded from the top by videotaping for $30 \mathrm{~min}$. The rearing number was counted manually. The total moving distance and the time spent in the four corners and the center area were quantified with the Smart Video Tracking System (Panlab).

Novel Object Recognition Test. After completion of the open field experiment, mice remained in the box for an additional 30 min. One day later, mice were returned to the same test box for another $30 \mathrm{~min}$. On day 3 , the mice were placed into the same test box for $30 \mathrm{~min}$, after which a novel white paper cup $(7.5 \mathrm{~cm}$ in diameter and $9.5 \mathrm{~cm}$ in height) was securely placed upside down in the center of the box. The exploratory activities of the mice regarding the novel cup were observed for an additional $10 \mathrm{~min}$. The time spent within a diameter of $20 \mathrm{~cm}$ from the object (center access) was assessed using the Smart Video Tracking System.

Elevated Plus Maze. The maze consisted of two open arms (30 $\times 5 \mathrm{~cm})$ and two enclosed arms $(30 \times 5 \times 14 \mathrm{~cm})$ that extended from a central platform $(5 \times 5 \mathrm{~cm})$. Animals were place into the central area facing one open arm and allowed to explore the maze. The movement was recorded by videotaping for $10 \mathrm{~min}$. The time spent in the open arms, the closed arms, and the central area was quantified with the Smart Video Tracking System.

Y Maze. Immediate memory was tested with a Y-maze apparatus consisting of three identical arms of enclosed Plexiglas (40 $\times 4.5 \times 12 \mathrm{~cm}) 120^{\circ}$ apart. Each mouse was placed at the end of one arm facing the center and allowed to freely explore for $8 \mathrm{~min}$. The movement in the Y maze was videorecorded from the top. The series of arm entries was analyzed with the Smart Video Tracking System. Actual alternation was defined as consecutive entries into each of the three arms without repetition (for exam- ple, $\mathrm{ABC}, \mathrm{BCA}, \mathrm{CAB})$. Spontaneous alternation was defined by dividing the number of actual alternations by the number of possible alternations (total arm entries -2).

Statistical Analysis

Data are presented as mean values \pm SEM, with $n$ indicating the number of animals analyzed. Statistical analysis was performed using the independent samples t test. All analyses were performed with the software SPSS (version 10.0.7C, SPSS Inc., Chicago, Ill., USA).

\section{Results}

\section{Generation of CINAP Knockout Mice}

The mouse CINAP gene is located at chromosome $\mathrm{X}$ $64.0 \mathrm{cM}$; the entire CINAP coding region is distributed among seven exons (fig. 1a). To disrupt CINAP expression, the recombineering system [14] was used to introduce a loxP site in front of the translational start codon and a Neo cassette flanked by FRT and loxP sites into intron 1 (fig. 1a). Seven targeted ES cell lines were identified by screening 383 clones; two of these lines were then used for blastocyst injection to generate chimeric mice. After germline transmission, mice carrying the targeted allele were then crossed to Act-Flp mice [16] to remove the Neo cassette. Mice carrying the floxed allele (fig. 1a) can be used to generate global knockout mice as well as tissuespecific knockout mice. In this report, we crossed our mice to E2A-cre mice [15] to create a global CINAP knockout mouse line. Genomic PCR (fig. 1b) and genomic Southern blotting (fig. 1c) confirmed the deletion of the first exon of CINAP. As CINAP is X-linked, we focused on the phenotypes of hemizygous males in the following study.

\section{Basic Characteristics of CINAP Knockout Mice Are Normal}

In general, CINAP knockout males appeared normal and healthy (fig. 2a) and were fertile. Their body weights were indistinguishable from those of wild-type littermates (fig. 2a, b). In addition, the gross appearances of CINAP knockout mouse brains were also normal (fig. 2cf), suggesting that the lack of CINAP does not impact gross neuroanatomy.

To facilitate the analysis of the CINAP knockout mice, we generated rabbit polyclonal and mouse monoclonal antibodies against mouse CINAP (fig. 3a, b). As the mouse 2G9 monoclonal antibody provided a strong and specific signal (fig. 3b), we used this monoclonal antibody for analysis of CINAP protein expression in the brain. 


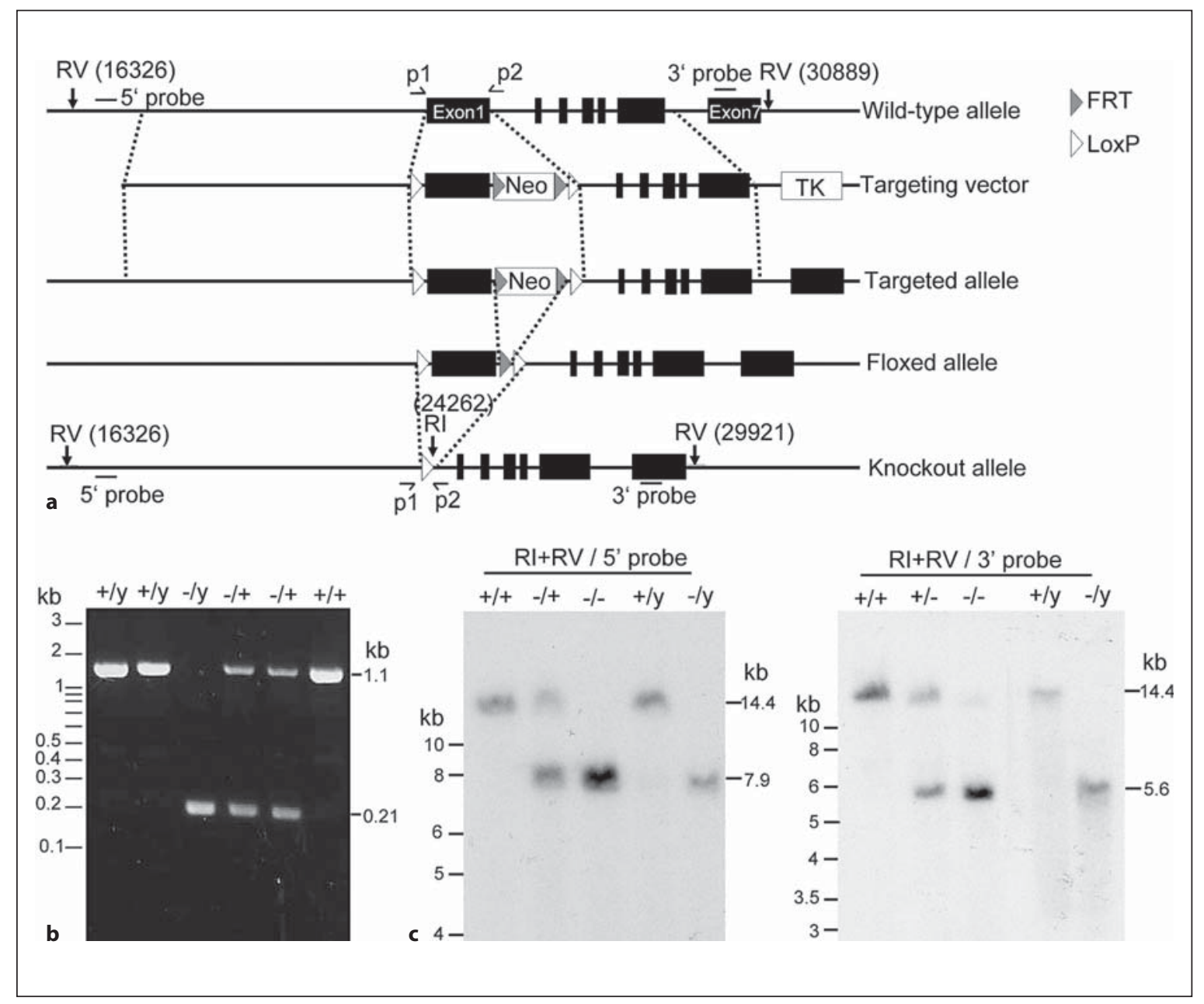

Fig. 1. Generation of CINAP knockout mice. a Schematic diagram of the genomic organization of the mouse CINAP gene and design of the CINAP knockout. Black boxes indicate CINAP exons. The Flp-FRT recombination system was used to eliminate the Neo cassette from the targeted allele. The Cre-LoxP recombination system was used to knock out the first exon of CINAP from the floxed allele. The positions of the EcoRI (RI) and EcoRV (RV) restriction enzyme sites and the $5^{\prime}$ and $3^{\prime}$ flanking probes used in Southern blotting are indicated. Primers p1 and p2 were used for genomic
PCR. b Genotyping by genomic PCR with primers $\mathrm{p} 1$ and $\mathrm{p} 2$. The PCR product lengths are 1.1 and $0.21 \mathrm{~kb}$ for the wild-type and knockout alleles, respectively. c Genomic Southern blotting using $5^{\prime}$ and $3^{\prime}$ flanking probes. For the wild-type allele, the EcoRI/EcoRV double-digested genomic DNA fragment is $14.4 \mathrm{~kb}$ in length. For the knockout allele, the fragments detected by the $5^{\prime}$ and $3^{\prime}$ probes are 7.9 and $5.6 \mathrm{~kb}$, respectively. Both female $(+/+,+/-,-/-)$ and male $(+/ y,-/ y)$ mice were analyzed.

\section{NMDAR2b Expression Is Not Altered in CINAP}

Knockout Mice

As CINAP was previously shown to regulate NMDAR2b expression through the interaction with CASK and Tbrl in cultured hippocampal neurons [9], we wondered whether CINAP deletion affected NMDAR2b protein expression in the brain. Adult mouse brains were first analyzed. Total homogenates of various brain regions were prepared and immunoblotted with an antiNMDAR $2 b$ antibody. Unexpectedly, NMDAR2b protein 


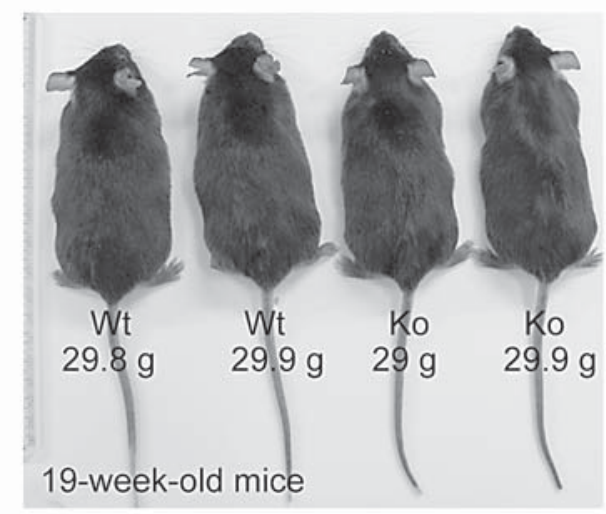

a

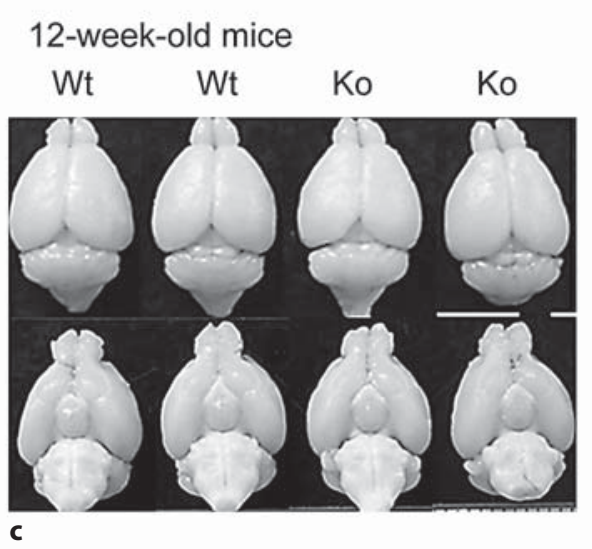

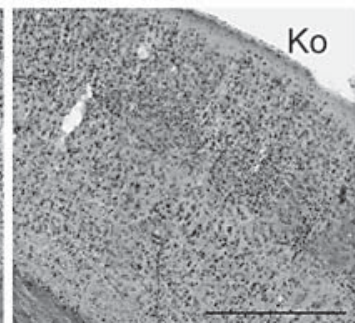
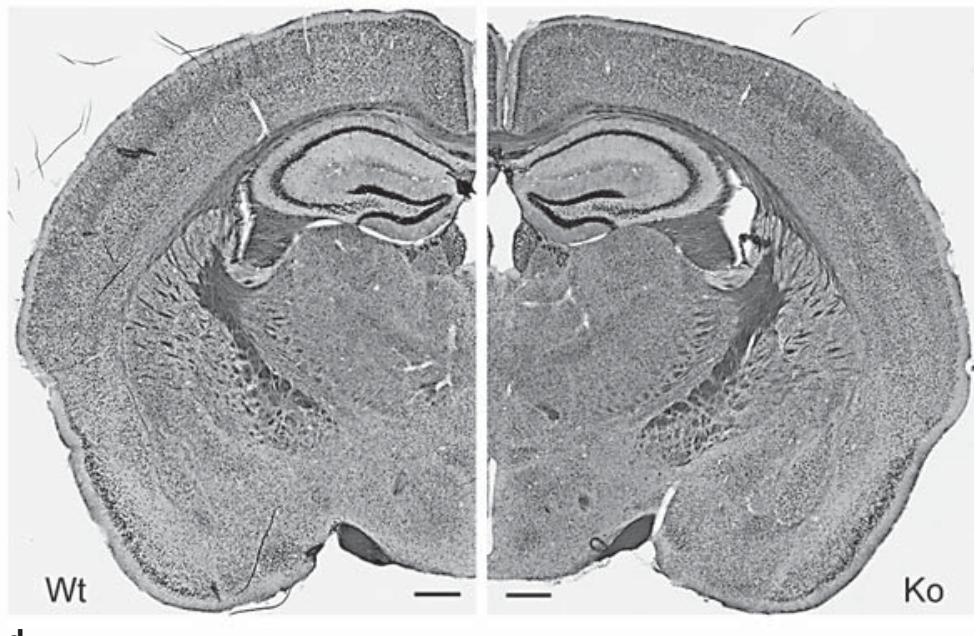

d

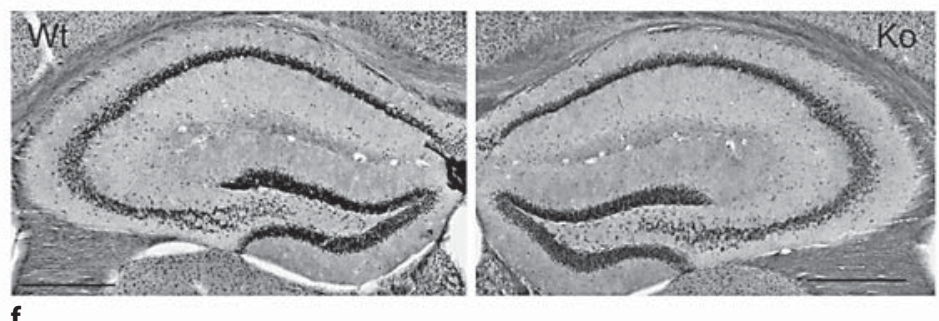

Fig. 2. The basic characteristics of CINAP knockout mice do not substantially differ from wild-type littermates. a Appearance of 19-week-old CINAP knockout (Ko) mice and wild-type (Wt) littermates. The body weights of the mice are indicated. $\mathbf{b}$ The mean body weights of CINAP Ko mice (triangles) and Wt littermates (squares) from 3 to 20 weeks. c Gross appearance of mouse brains. d-f Global brain anatomy of CINAP Ko mice and Wt littermates. Coronal sections of mouse brains were stained using Luxol fast blue and cresyl violet. Higher magnification images of cortex and hippocampus are shown in e and $\mathbf{f}$, respectively. Scale bars $=500$ $\mu \mathrm{m}$. 


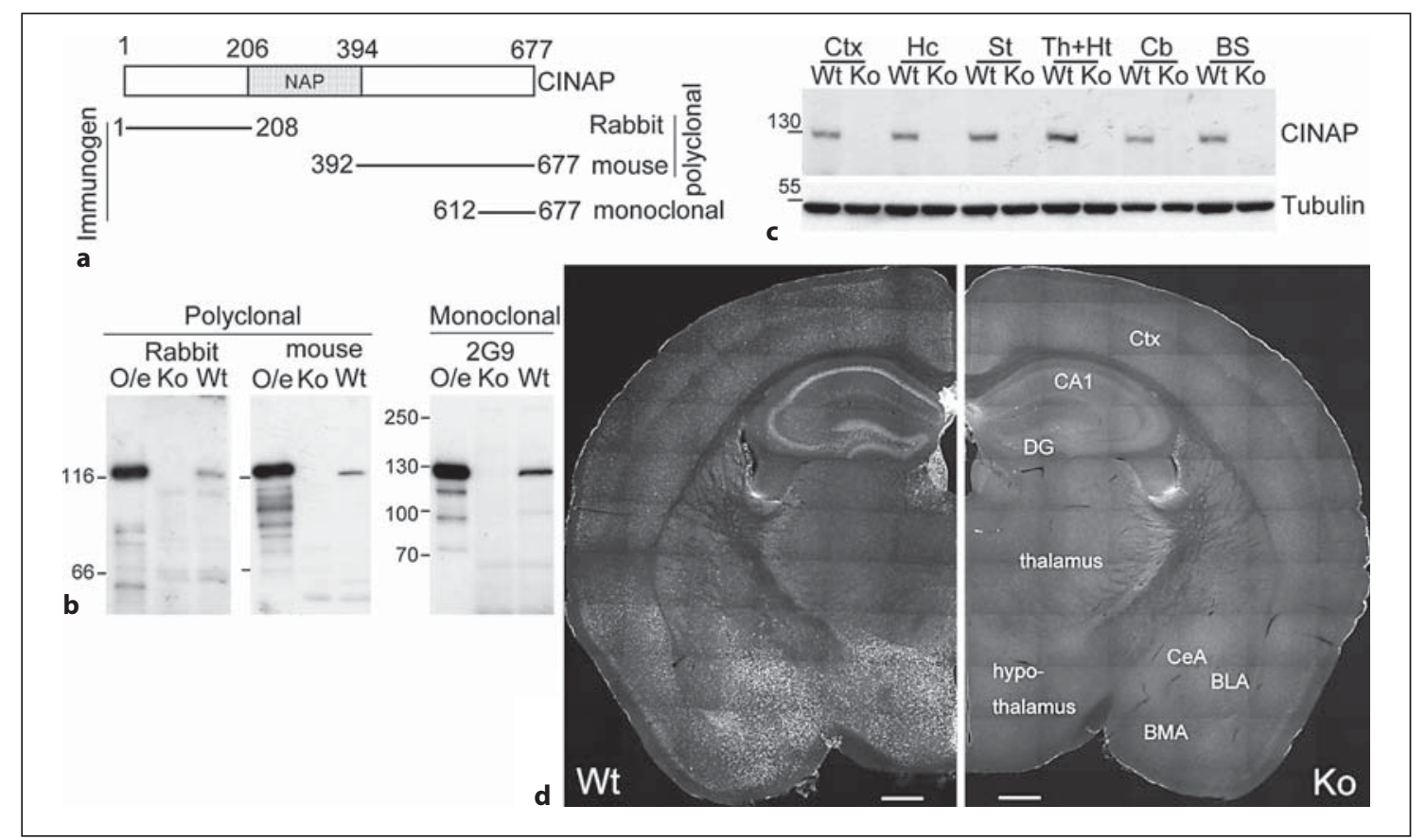

Fig. 3. Characterization of CINAP antibodies and CINAP distribution in the mouse brain. a Schematic domain structure of CINAP protein and the CINAP fragments used as immunogens to generate rabbit and mouse polyclonal antibodies and mouse monoclonal antibody. $\mathbf{b}$ Characterization of CINAP antibodies by immunoblotting. Protein extracts prepared from Neuro-2A cells overexpressing CINAP (O/e) and wild-type (Wt) and CINAP knockout (Ko) brains were immunoblotted with the indicated antibodies. $\mathrm{c}$ Distribution of CINAP in the mouse brain analyzed by immunoblotting. d Distribution of CINAP protein in mouse brain as revealed by indirect fluorescence immunostaining. Note the distribution of CINAP formed a gradient from dorsal-low to ventral-high. $\mathrm{BLA}=$ Basolateral amygdala; $\mathrm{BMA}=$ basomedial amygdala; $\mathrm{BS}$ = brain stem; $\mathrm{CA} 1=$ Cornu Ammonis area 1 in hippocampus; $\mathrm{Cb}=$ cerebellum; $\mathrm{CeA}=$ central amygdala; $\mathrm{Ctx}=\mathrm{ce}-$ rebral cortex; DG = dentate gyrus; $\mathrm{Hc}=$ hippocampus; $\mathrm{Ht}=$ hypothalamus; $\mathrm{St}=$ striatum; $\mathrm{Th}=$ thalamus. Scale bar $=500 \mu \mathrm{m}$. levels were comparable in CINAP knockout mice and wild-type littermates, regardless of the brain region analyzed (fig. $4 \mathrm{a}, \mathrm{b}, \mathrm{n}=3$ ). Since NMDAR2b expression is developmentally regulated [18-20], we then investigated whether CINAP is involved in the regulation of NR2b expression at the early developmental stage. Two time points were examined, which are embryonic day 18.5 (E18.5) and postnatal day 14 (P14). Similar to the results obtained with adult mouse brains, the NR2b expression levels did not differ noticeably between CINAP knockout mice and wild-type littermates at both E18.5 (fig. 5a, $\mathrm{n}=$ 3) and P14 (fig. 5b, $n=3$ ). In conclusion, these data indicate that CINAP deletion did not apparently influence the in vivo baseline expression of NMDAR2b.

Hippocampus- and Amygdala-Dependent Associative Memory Is Normal in CINAP Knockout Mice

Although the NMDAR2b protein levels in CINAP knockout mice were comparable to those in wild-type lit- termates (fig. 4, 5), we assessed mouse learning and memory behaviors to directly investigate the involvement of CINAP in the regulation of learning and memory behaviors. We included mice aged 3-4 months as well as mice 13-15 months old. We first performed the Y-maze behavioral assay to examine immediate memory by discerning which maze arm was entered last in a Y-shaped maze. Although spontaneous alternation, as determined by examining the sequence of visits to all three arms for consecutive choices, was slightly lower in CINAP knockout mice than in wild-type littermates, particularly in 3- to 4-month-old mice, the differences were not statistically significant (fig. 6a; for 3- to 4-month-old mice, Wt, $\mathrm{n}=$ $18, \mathrm{KO}, \mathrm{n}=22$; for 13 - to 15 -month-old mice, both Wt and $\mathrm{KO}, \mathrm{n}=14$ ), suggesting that CINAP deletion does not obviously influence immediate memory.

The classical Pavlovian paradigms of CTA and fear conditioning were used to assess associative memory of CINAP knockout mice. In CTA, an amygdala-dependent 
Fig. 4. Expression of NMDAR2b (NR2b) in different brain regions does not substantially differ between adult wild-type $(\mathrm{Wt})$ and CINAP knockout (Ko) mice ( $\mathrm{n}=$ 3 per group). a Immunoblotting. Fourmonth-old mice were used for the analysis of NR2b expression. The indicated brain homogenates (10 $\mu \mathrm{g} /$ lane) were immunoblotted with anti-NR2b, anti-CINAP, and anti- $\beta$-actin antibodies. As expected, anti-CINAP signal was absent from the CINAP Ko brains. Hipp. = Hippocampus. b Quantitation of the relative NR2b protein levels. Data represent mean \pm SEM.

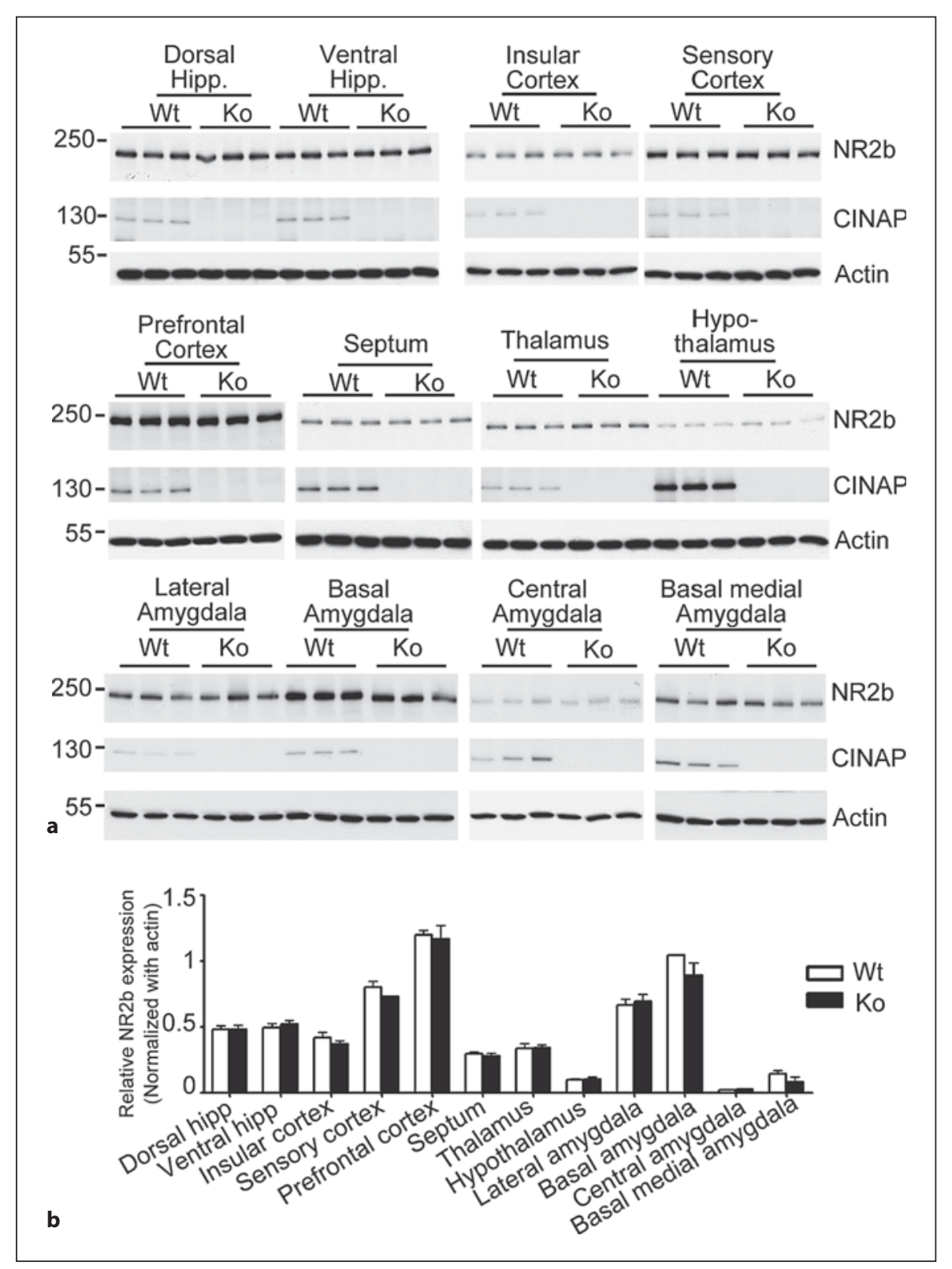

associative memory, mice learn to associate a novel food (sucrose) with LiCl-induced vomiting and abdominal pain (fig. 6b). Two days after training, similar to their wild-type littermates, CINAP knockout mice remembered the sucrose-induced aversive response and drank less sucrose solution but more water, leading to a low sucrose preference (fig. $6 \mathrm{c}$; both $\mathrm{Wt}$ and $\mathrm{KO}, \mathrm{n}=20$ ). This observation suggests that amygdala-dependent memory is normal in CINAP knockout mice. We further examined whether CINAP is involved in CTA extinction by measuring sucrose preference every other day. Similar to their wild-type littermates, CINAP knockout mice drank increasing volumes of sucrose solution from day 4 to day 20 after training. Although the sucrose preference of CINAP knockout mice was slightly higher than that of wild-type littermates, the difference was not statistically significant (fig. 6c), suggesting that deletion of CINAP does not impact CTA extinction.

We employed fear conditioning to further assess the learning and memory behaviors of CINAP knockout mice. Mice were trained to associate emotional neutral conditioned stimuli (a novel environmental cue and auditory 
Fig. 5. The NR2b expression levels at E18.5 and P14 are comparable between CINAP knockout mice and wild-type littermates. $10 \mu \mathrm{g}$ of total homogenates was loaded for immunoblotting with anti-NR2b, anti-CINAP, and anti- $\beta$-actin antibodies. a E18.5. b P14. Quantitative analyses of immunoblots are shown in histograms. $\mathrm{n}=3$. Data represent mean \pm SEM.

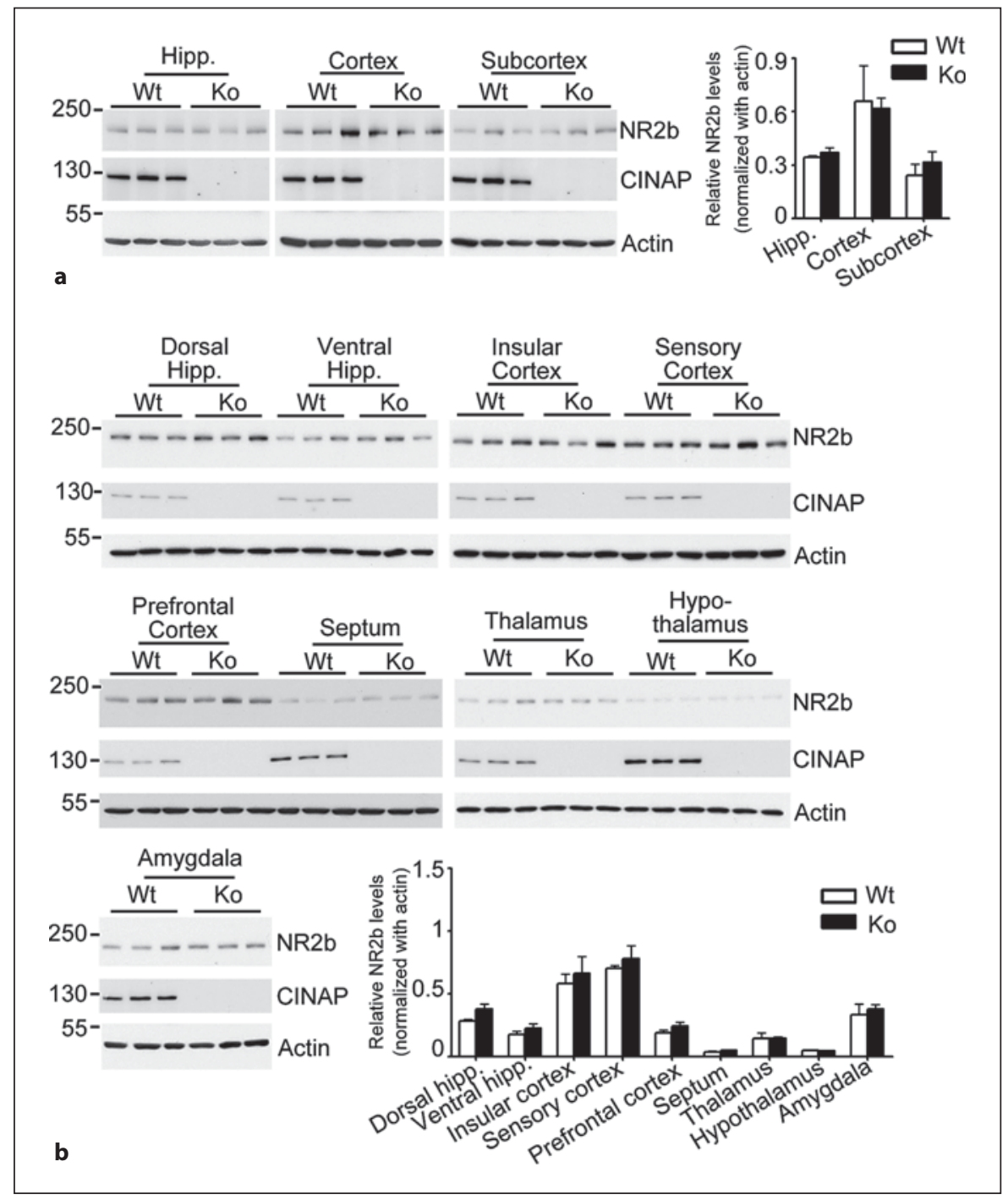

cue) with an aversive unconditioned stimulus (an electronic foot shock; fig. 6d). Auditory fear conditioning requires the amygdala, and the hippocampus is also involved in contextual fear conditioning. Memory in this paradigm is reflected in freezing behaviors. Although the basal measurements of the freezing response were significantly different between CINAP knockout mice and wild-type littermates (fig. 6e; 3 - to 4-month-old mice, $\mathrm{n}=12$, basal: $\mathrm{t}_{22}$ $=-2.898, \mathrm{p}=0.008 ; 13$ - to 15 -month-old mice, $\mathrm{n}=14$, basal: $\mathrm{t}_{26}=3.594, \mathrm{p}=0.001$ ), the freezing responses directly after three electronic foot shocks were comparable (fig. 6e). For associative memory, neither contextual nor auditory fear conditioning was affected in CINAP knockout mice regardless of the age of mice (fig. 6e, upper panel for 3- to 4-month-old mice; lower panel for 13- to 15-month- old mice). Combined with the observations in CTA, these analyses suggest that CINAP deletion does not impair hippocampus- or amygdala-dependent associative memory.

\section{CINAP Knockout Mice Have Higher Locomotor and} Exploratory Activities in a Novel Environment

We then assessed the impact of CINAP deletion on mouse behaviors, including the open field test and the elevated plus maze. For the open field test, the mice were placed in a new box for a period of $30 \mathrm{~min}$, and the horizontal movement (travel distance) and vertical movement (rearing) in the box were recorded. The cumulative travel distances of 3- to 4-month-old and 13- to 15-month-old CINAP knockout mice were slightly but significantly longer than those of their wild-type littermates (fig. 7a; 3- to 


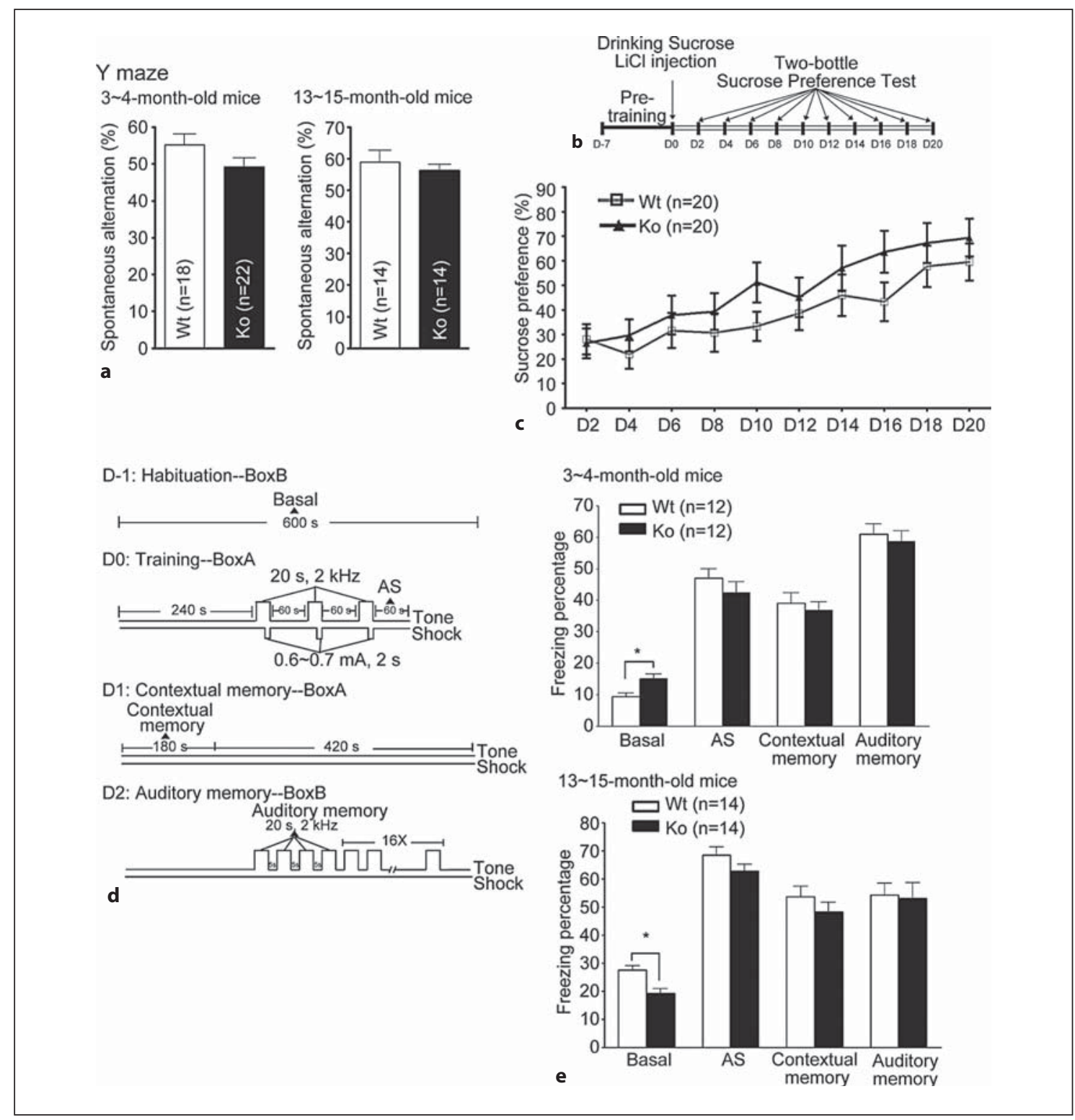

Fig. 6. Learning and memory behaviors are unaffected in CINAP knockout $(\mathrm{Ko})$ mice compared with wild-type $(\mathrm{Wt})$ littermates. a Immediate memory, as assessed by the Y maze, did not statistically differ between Ko and Wt mice. $\mathbf{b}$ Schematic diagram of the CTA test (see 'Materials and Methods'). c The sucrose preference of 3- to 4-month-old CINAP Ko mice (triangles) and Wt littermates (squares) in the CTA test. $\mathbf{d}$ Schematic diagram of fear con- ditioning. At day 1 (D1), memory of contextual fear conditioning was examined. At day 2 (D2), auditory fear conditioning was analyzed. AS = After stimulation. e Neither contextual nor auditory fear conditioning was affected in CINAP knockout mice, though the basal freezing responses were slightly different. Mean value \pm SEM is depicted. ${ }^{*} \mathrm{p}<0.05$.
4 -month-old mice, Wt, $\mathrm{n}=14 ; \mathrm{KO}, \mathrm{n}=16 ; 6 \mathrm{~min}$ : $\mathrm{t}_{28}=-2.364, \mathrm{p}=0.025 ; 9 \mathrm{~min}: \mathrm{t}_{28}=-2.17, \mathrm{p}=0.038 ; 12 \mathrm{~min}:$ $\mathrm{t}_{28}=-2.329, \mathrm{p}=0.027 ; 15$ min: $\mathrm{t}_{28}=-2.257, \mathrm{p}=0.031 ; 18$ min: $\mathrm{t}_{28}=-2.122, \mathrm{p}=0.042 ; 30 \mathrm{~min}: \mathrm{t}_{28}=-2.095, \mathrm{p}=0.045$; 13- to 15-month-old mice, both Wt and $\mathrm{KO}, \mathrm{n}=14$; $\mathrm{t}_{26}=$ $-3.342, \mathrm{p}=0.0025)$. In addition, the number of rearings was significantly higher in CINAP knockout mice (fig. 7a; 3 - to 4-month-old mice, $\mathrm{t}_{28}=-4.464, \mathrm{p}=0.0001 ; 13$ - to 15 -month-old mice, $\left.\mathrm{t}_{26}=-3.056, \mathrm{p}=0.005\right)$. These data suggest that exploratory activity is higher in CINAP knockout mice. To further confirm this observation, the novel object recognition was examined at the end of the 
Fig. 7. Characterization of CINAP knockout (Ko) mice and wild-type (Wt) littermates using the open field test and the elevated plus maze. a The open field test and novel object recognition. The results of travel distance, number of rearings, ratio of time spent in the central and corner area, and time spent to explore novel objects are summarized. The CINAP knockout mice exhibited significant increases in travel distance and rearing compared to their wild-type littermates. b Elevated plus maze. Percentages of time spent in the closed arm, the open arm, and the central region are shown. ${ }^{*} \mathrm{p}<0.05$.

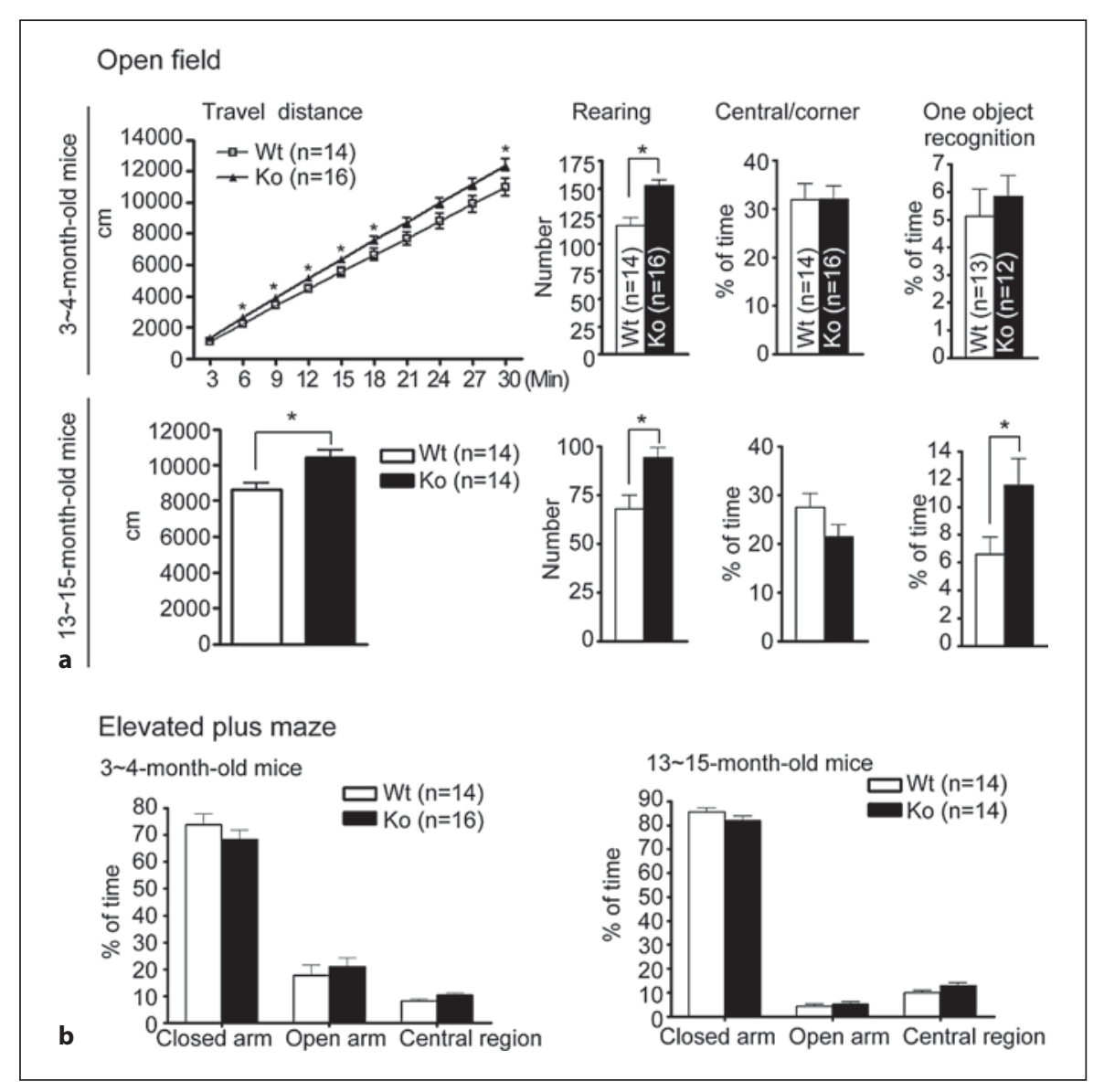

open field test. For 3- to 4-month-old mice, the total time required to approach the novel object was similar between CINAP knockout mice and their wild-type littermates (fig. 7a, upper right panel). However, at the age of 13-15 months, CINAP knockout mice spent significantly more time approaching the novel object (fig. 7a, lower panel; 13to 15 -month-old mice, $\left.\mathrm{t}_{26}=-2.172, \mathrm{p}=0.039\right)$. In conclusion, these analyses support a role of CINAP in locomotor and exploratory activities in a novel environment.

We also analyzed the anxiety of the mice during the open field test. CINAP knockout mice and their wildtype littermates spent equal fractions of time in the center of the arena regardless of age (fig. 7a, central/corner), suggesting a lack of anxiety in CINAP knockout mice. To confirm this observation, we implemented the elevated plus maze and found that 3- to 4-month-old and 13- to 15-month-old CINAP knockout mice spent similar amounts of time as their wild-type littermates in the open arm (fig. 7b; 3- to 4-month-old mice, $\mathrm{Wt}, \mathrm{n}=14 ; \mathrm{KO}, \mathrm{n}=$ 16 ; 13 - to 15 -month-old mice, both Wt and $\mathrm{KO}, \mathrm{n}=14$ ), indicating that CINAP deletion does not impact anxiety.

\section{Higher Exploratory Activity of CINAP Knockout Mice} in Home Cages

We also assessed the locomotor and exploratory behaviors of CINAP knockout mice in their home cages through videorecording and automated analysis (see 'Materials and Methods'), quantifying the frequency and duration of the behaviors. More than 20 different home cage behaviors and the circadian rhythm of these behaviors can be analyzed with this technology [21]. Under regular housing conditions, it is clear that CINAP knockout mice had normal circadian rhythms (fig. 8 ; $\mathrm{Wt}, \mathrm{n}=14$; $\mathrm{KO}, \mathrm{n}=16)$. In the home cage, although the travel distance of CINAP knockout mice was slightly longer than that of their wild-type littermates, the difference was not statistically significant (fig. 8a, 9a). Consistent with observations in the open field test, the CINAP knockout mice spent significantly more time rearing (fig. $8 \mathrm{~b}$, $21: 00$ h: $\mathrm{t}_{28}=-2.352, \mathrm{p}=0.025,22: 00 \mathrm{~h}: \mathrm{t}_{28}=-2.698, \mathrm{p}=$ 0.011; fig. 9b, night: $\mathrm{t}_{28}=-2.184, \mathrm{p}=0.037$ ), jumping (fig. $8 \mathrm{k}, 21: 00 \mathrm{~h}: \mathrm{t}_{28}=-2.511, \mathrm{p}=0.018$; fig. $9 \mathrm{k}$, day: $\mathrm{t}_{28}=$ $-2.109, \mathrm{p}=0.043$ ), and repetitive jumping (fig. 8l, 22:00 h: 
$\mathrm{t}_{28}=-2.362, \mathrm{p}=0.025,04: 00 \mathrm{~h}: \mathrm{t}_{28}=-2.06, \mathrm{p}=0.048 ;$ fig. 9l, night: $\mathrm{t}_{28}=-2.31, \mathrm{p}=0.028$ ) than their wild-type littermates, demonstrating that CINAP deletion enhances the vertical movement of mice. We also noticed that CINAP knockout mice displayed more sniffing behavior in their home cages than their wild-type littermates (fig. $8 \mathrm{c}, 21: 00 \mathrm{~h}: \mathrm{t}_{28}=-2.542, \mathrm{p}=0.016,22: 00 \mathrm{~h}: \mathrm{t}_{28}=$ $-2.511, \mathrm{p}=0.018,23: 00 \mathrm{~h}: \mathrm{t}_{28}=-3.155, \mathrm{p}=0.003,24: 00 \mathrm{~h}:$ $\mathrm{t}_{28}=-2.088, \mathrm{p}=0.045,01: 00 \mathrm{~h}: \mathrm{t}_{28}=-2.596, \mathrm{p}=0.014$, 04:00 h: $\mathrm{t}_{28}=-2.258, \mathrm{p}=0.031,05: 00 \mathrm{~h}: \mathrm{t}_{28}=-2.065, \mathrm{p}=$ 0.048; fig. 9c, night: $\mathrm{t}_{28}=-2.783, \mathrm{p}=0.009$ ), consistent with the observation that CINAP knockout mice have higher exploratory activity. CINAP knockout mice also spent more time eating (fig. $8 \mathrm{~h}, 01: 00 \mathrm{~h}: \mathrm{t}_{28}=-2.837, \mathrm{p}=$ 0.008; fig. 9h, night: $\mathrm{t}_{28}=-2.347, \mathrm{p}=0.026$ ) and chewing (fig. 8i, 22:00 h: $\mathrm{t}_{28}=-2.974, \mathrm{p}=0.005,01: 00 \mathrm{~h}: \mathrm{t}_{28}=$ $-2.383, \mathrm{p}=0.024$; fig. 9i, night: $\left.\mathrm{t}_{28}=-2.972, \mathrm{p}=0.006\right)$ in their home cages than their wild-type littermates. Taken together, these observations indicate that CINAP knockout mice exhibit higher exploratory activities than their wild-type littermates, even in the home cage.

\section{Discussion}

\section{CINAP and Learning/Memory}

Human CINAP is located at Xp11.2, and is included in the nonspecific X-linked mental retardation MRX81 locus (Xp11.2-Xq12) [22]. Although we previously determined that CINAP regulates NMDAR2b expression in cultured hippocampal neurons, NMDAR2b protein levels were not significantly changed in the brains of our CINAP knockout mice. The Y-maze, fear conditioning, and CTA tests also revealed that the performances of CINAP knockout mice in immediate and associative memories were comparable with those of wild-type littermates. Taken together, these observations suggest that CINAP deletion does not influence the learning and memory abilities of mice.

It is unclear why CINAP did not appear to regulate NMDAR2b expression in vivo, and several possible scenarios may explain this unexpected observation. First, there are more than a dozen nucleosome assembly proteins defined by the conserved nucleosome assembly protein domain in the mouse genome, including CINAP [23, 24]. Since the nucleosome assembly domain of CINAP is the interacting domain for CASK [9], other nucleosome assembly proteins are likely to compensate for the CINAP deletion in the brain, rescuing the deficits in NMDAR2b expression and learning/memory performance. Another possibility is that CINAP may regulate NMDAR2b expression and learning/memory performance under specific conditions that were not pertinent in our assays. We previously showed that the interactions among CASK, CINAP, and Tbrl are enhanced by protein kinase A phosphorylation of CASK $[25,26]$. Consequently, NMDAR2b protein levels and promoter activity increase upon protein kinase A activation $[25,26]$. Perhaps the main role of CINAP in the regulation of NMDAR2b expression is to respond to the protein kinase A pathway; if this is the case, the effect of CINAP deletion on NMDAR2b expression may not be obvious in vivo. More investigations are required to examine these possibilities.

\section{CINAP and Exploratory Locomotor Activity of Mice}

We observed a remarkable increase in the exploratory and locomotor activities of CINAP knockout mice compared to their wild-type littermates. In the literature, hundreds of mouse genetic models have been characterized by abnormal locomotor or exploratory activities (see the database 'Mouse genome informatics' at the website: http://www.informatics.jax.org/searches/MP_form. shtml). It is clear that the relationship between genes and locomotor and exploratory activities is not monotonic. At the moment, the molecular mechanism underlying the role of CINAP in locomotor and exploratory activities remains uncertain. Since CINAP acts as nucleosome assembly protein, it will be certainly interesting to compare the gene expression profile of CINAP knockout mice with that of wild-type littermates by microarray analysis in the future. By analyzing CINAP target genes, we may extract useful information explaining how CINAP regulates locomotion and exploration in mice.

An analysis of the brain expression patterns of genes related to locomotion led to the suggestion that genes that are associated with locomotor hyperactivity are more expressed in the cerebral cortex, amygdala and hippocampus compared with the genes unrelated to locomotion [27]. The CINAP protein expression pattern in brain actually fits very well into this category. In addition to locomotion, amygdala is also involved in the regulation of exploratory activity in rodents [28]. CINAP expression in amygdala associated nucleus may therefore contribute to regulation of exploratory activity. Our results also indicated high expression levels of CINAP protein in hypothalamus, an important brain region that controls many physiological responses through neural circuits and neuroendocrine systems. Previous studies have shown that modulation of the neuronal activity in the hypothalamus influences the exploratory activity of mice [29-31]. More- 


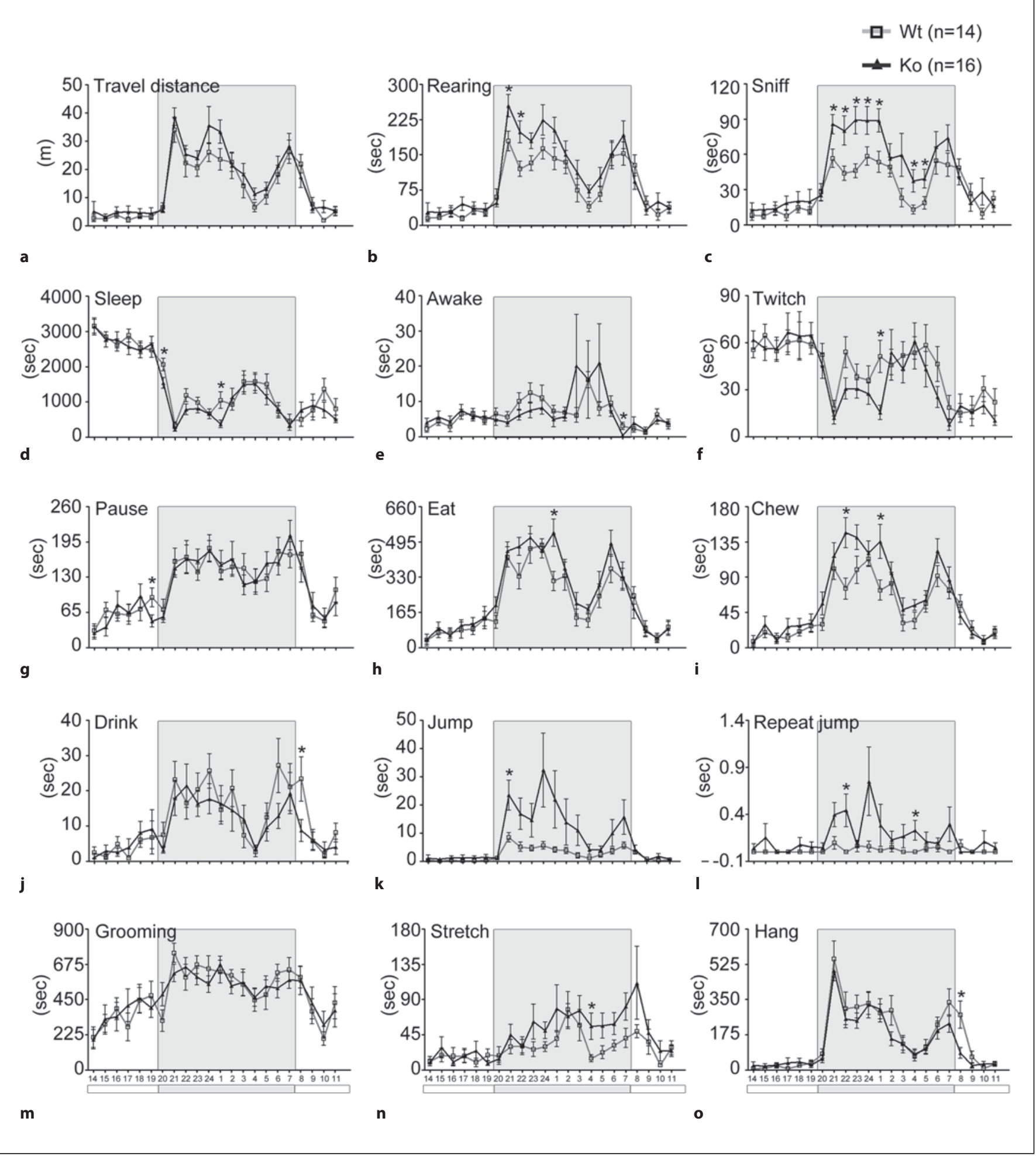

Fig. 8. Deletion of CINAP results in high exploratory and locomotor activity in the home cage. A total of 15 home cage behaviors were analyzed using the HomeScan system. Nighttime periods (from 20:00 to 08:00 h) are indicated with the grey box. With the exception of travel distance in a, the time spent for the indicated behaviors within the indicated time windows are shown. CINAP knockout (Ko) mice and wild-type (Wt) littermates exhibited the similar circadian patterns. Note CINAP knockout mice spent more time on rearing, sniffing, pumping, eating and chewing. ${ }^{*} \mathrm{p}<0.05$. 
Fig. 9. CINAP knockout mice spend more time on exploratory and locomotor behaviors in the home cage. Means of the total distance or time spent for specific behaviors shown in figure 7 were summarized. Error bars indicate SEM. ${ }^{*} \mathrm{p}<0.05$.

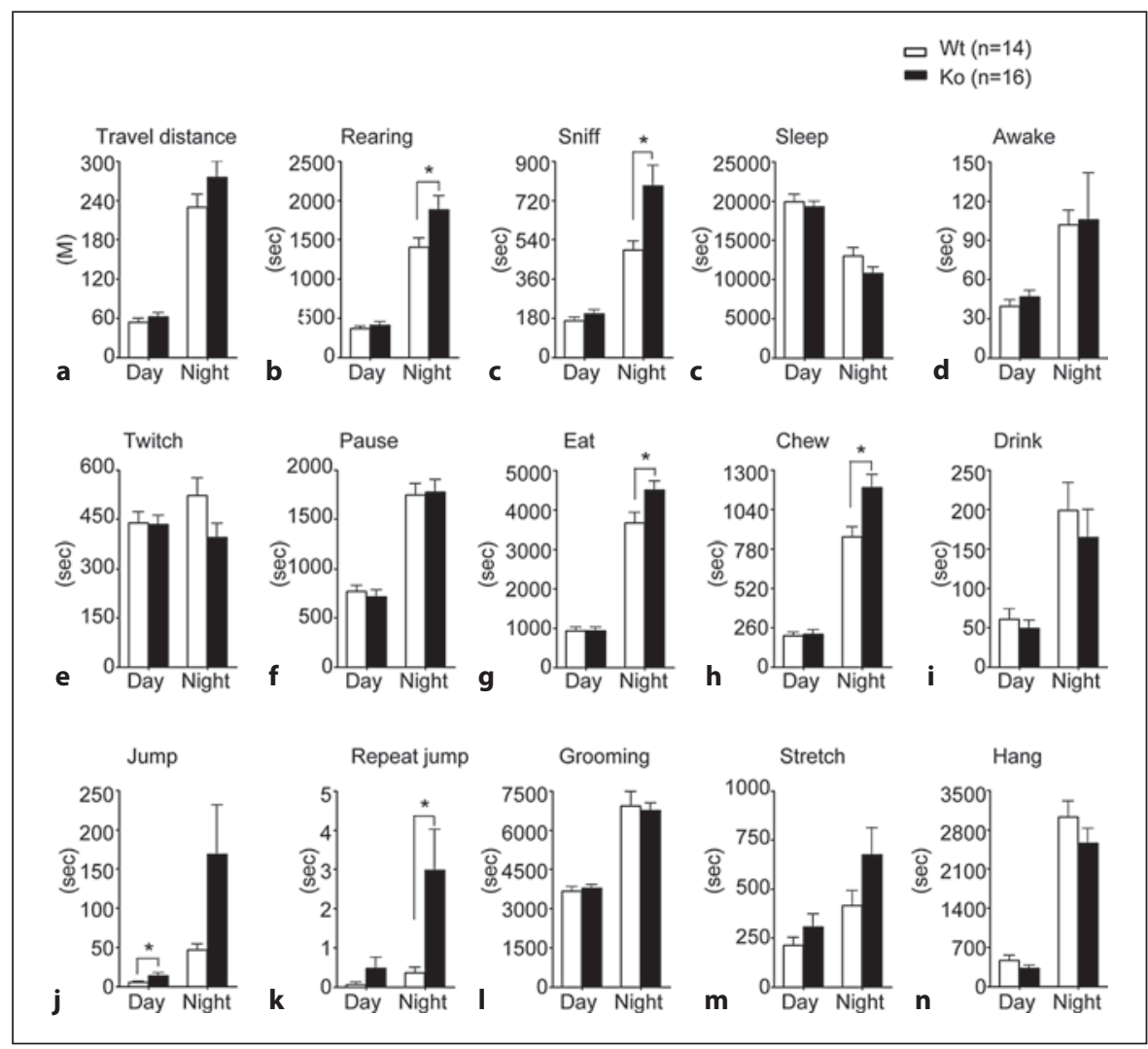

over, it has been documented that hippocampus, cerebral cortex, and amygdala all project either directly or indirectly to the hypothalamus $[32,33]$ and thus influence the neural activity of the hypothalamus. Therefore, CINAP expression in these brain areas may modulate the expression of specific genes and thus control the exploratory and locomotor activities of mice.

\section{Other Physiological Functions of CINAP}

Previous studies demonstrated that CINAP is a downstream target of TGF- $\beta 1[11,34,35]$ and is involved in downregulation of the cell cycle $[12,36]$, suggesting that CINAP is involved in development and/or tumor growth. However, deletion of CINAP from mice did not obviously influence brain development. Before the age of $\sim 15$ months, the CINAP knockout mice grew normally, and the global appearances and body weights of the CINAP knockout mice were also comparable to their wild-type littermates. This is not clear at this moment whether CINAP knockout results in tumor formation or other defects in mice older than 15 months. More detailed examinations need to be performed to determine whether CINAP deletion influences tumor formation.
In conclusion, our study indicates that CINAP regulates the exploratory and locomotor activities of mice. Although CINAP was previously shown to modulate NMDAR2b expression in cultured hippocampal neurons, deletion of CINAP in mice influenced neither brain NMDAR2 expression nor learning/memory behaviors. Perhaps other nucleosome assembly proteins compensate for the effect of the CINAP knockout. More investigations need to be carried out to examine whether CINAP contributes to tumor formation in vivo.

\section{Acknowledgements}

We thank Dr. Neal Copeland for plasmids of the recombineering system, Dr. Po-Wu Gean and Mr. Sheng-Chun Mao for technical assistance on fear conditioning, the Transgenic Core Facility, the Institute of Molecular Biology, Academia Sinica for technical assistance, and Dr. Heiko Kuhn for English editing. This work was supported by grants from Academia Sinica (to Y.-P.H.), the National Health Research Institute (to Y.-P.H., NHRI-EX989403NI), and the National Science Council (to Y.-P.H., NSC 992321-B-001-032). The authors declare no conflicting financial interests. 


\section{References}

1 Hackett A, Tarpey PS, Licata A, Cox J, Whibley A, Boyle J, Rogers C, Grigg J, Partington M, Stevenson RE, Tolmie J, Yates JR, Turner G, Wilson M, Futreal AP, Corbett M, Shaw M, Gecz J, Raymond FL, Stratton MR, Schwartz CE, Abidi FE: CASK mutations are frequent in males and cause X-linked nystagmus and variable XLMR phenotypes. Eur J Hum Genet 2010;18:544-552.

$\checkmark 2$ Tarpey PS, Smith R, Pleasance E, et al: A sys- 15 tematic, large-scale resequencing screen of $\mathrm{X}$-chromosome coding exons in mental retardation. Nat Genet 2009;41:535-543.

- 3 Piluso G, D’Amico F, Saccone V, Bismuto E, Rotundo IL, Di Domenico M, Aurino S, Schwartz CE, Neri G, Nigro V: A missense mutation in CASK causes FG syndrome in an Italian family. Am J Hum Genet 2009;84:162-177.

-4 Najm J, Horn D, Wimplinger I, Golden JA, Chizhikov VV, Sudi J, Christian SL, Ullmann R, Kuechler A, Haas CA, Flubacher A, Charnas LR, Uyanik G, Frank U, Klopocki E, Dobyns WB, Kutsche K: Mutations of CASK cause an X-linked brain malformation phenotype with microcephaly and hypoplasia of the brainstem and cerebellum. Nat Genet 2008;40:1065-1067.

$\checkmark 5$ Atasoy D, Schoch S, Ho A, Nadasy KA, Liu X, Zhang W, Mukherjee K, Nosyreva ED, Fernandez-Chacon R, Missler M, Kavalali ET, Sudhof TC: Deletion of CASK in mice is lethal and impairs synaptic function. Proc Natl Acad Sci USA 2007;104:2525-2530.

-6 Hsueh YP: Calcium/calmodulin-dependent serine protein kinase and mental retardation. Ann Neurol 2009;66:438-443.

7 Hsueh YP: The role of the MAGUK protein CASK in neural development and synaptic function. Curr Med Chem 2006;13:19151927.

8 Hsueh YP, Wang TF, Yang FC, Sheng M: Nuclear translocation and transcription regulation by the membrane-associated guanylate kinase CASK/lin-2. Nature 2000;404:298302.

-9 Wang GS, Hong CJ, Yen TY, Huang HY, Ou Y, Huang TN, Jung WG, Kuo TY, Sheng M, Wang TF, Hsueh YP: Transcriptional modification by a CASK-interacting nucleosome assembly protein. Neuron 2004;42:113-128.

10 Kuo TY, Hong CJ, Chien HL, Hsueh YP: Xlinked mental retardation gene CASK interacts with Bcl11A/CTIP1 and regulates axon branching and outgrowth. J Neurosci Res 2010;88:2364-2373.

-11 Ozbun LL, You L, Kiang S, Angdisen J, Martinez A, Jakowlew SB: Identification of differentially expressed nucleolar TGF-betal target (DENTT) in human lung cancer cells that is a new member of the TSPY/SET/NAP1 superfamily. Genomics 2001;73:179-193.

12 Chai Z, Sarcevic B, Mawson A, Toh BH: Setrelated cell division autoantigen-1 (CDA1) arrests cell growth. J Biol Chem 2001;276: 33665-33674.
13 Wang TF, Ding CN, Wang GS, Luo SC, Lin YL, Ruan Y, Hevner R, Rubenstein JL, Hsueh YP: Identification of TBR-1/CASK complex target genes in neurons. J Neurochem 2004; 91:1483-1492.

14 Liu P, Jenkins NA, Copeland NG: A highly efficient recombineering-based method for generating conditional knockout mutations. Genome Res 2003;13:476-484.

15 Lakso M, Pichel JG, Gorman JR, Sauer B, Okamoto Y, Lee E, Alt FW, Westphal H: Efficient in vivo manipulation of mouse genomic sequences at the zygote stage. Proc Natl Acad Sci USA 1996;93:5860-5865.

16 Rodriguez CI, Buchholz F, Galloway J, Sequerra R, Kasper J, Ayala R, Stewart AF, Dymecki SM: High-efficiency deleter mice show that FLPe is an alternative to Cre-loxP. Nat Genet 2000;25:139-140.

17 Lin CW, Huang TN, Wang GS, Kuo TY, Yen TY, Hsueh YP: Neural activity- and development-dependent expression and distribution of CASK interacting nucleosome assembly protein in mouse brain. J Comp Neurol 2006; 494:606-619.

18 Williams K, Russell SL, Shen YM, Molinoff PB: Developmental switch in the expression of NMDA receptors occurs in vivo and in vitro. Neuron 1993;10:267-278.

19 Monyer H, Burnashev N, Laurie DJ, Sakmann B, Seeburg PH: Developmental and regional expression in the rat brain and functional properties of four NMDA receptors. Neuron 1994;12:529-540.

20 Sheng M, Cummings J, Roldan LA, Jan YN, Jan LY: Changing subunit composition of heteromeric NMDA receptors during development of rat cortex. Nature 1994;368:144-147.

21 Steele AD, Jackson WS, King OD, Lindquist $S$ : The power of automated high-resolution behavior analysis revealed by its application to mouse models of Huntington's and prion diseases. Proc Natl Acad Sci USA 2007;104: 1983-1988.

-22 Annunziata I, Lanzara C, Conte I, Zullo A, Ventruto V, Rinaldi MM, D’Urso M, Casari G, Ciccodicola A, Miano MG: Mapping of MRX81 in Xp11.2-Xq12 suggests the presence of a new gene involved in nonspecific X-linked mental retardation. Am J Med Genet A 2003;118A:217-222.

23 Park YJ, Luger K: Structure and function of nucleosome assembly proteins. Biochem Cell Biol 2006;84:549-558.

24 Eitoku M, Sato L, Senda T, Horikoshi M: Histone chaperones: 30 years from isolation to elucidation of the mechanisms of nucleosome assembly and disassembly. Cell Mol Life Sci 2008;65:414-444.

25 Huang TN, Hsueh YP: CASK point mutation regulates protein-protein interactions and $\mathrm{Nr} 2 \mathrm{~b}$ promoter activity. Biochem Biophys Res Commun 2009;382:219-222.
26 Huang TN, Chang HP, Hsueh YP: CASK phosphorylation by PKA regulates the protein-protein interactions of CASK and expression of the NMDAR2b gene. J Neurochem 2010;112:1562-1573.

27 Mignogna P, Viggiano D: Brain distribution of genes related to changes in locomotor activity. Physiol Behav 2010;99:618-626.

28 Lukaszewska I, Korczynski R, Markowska A, Kostarczyk E: Emotionality and exploratory behavior following cortico-basomedial amygdala lesion in rat. Acta Neurobiol Exp (Wars) 1980;40:911-932.

29 Hashimoto H, Shintani N, Tanaka K, Mori W, Hirose M, Matsuda T, Sakaue M, Miyazaki J, Niwa H, Tashiro F, Yamamoto K, Koga K, Tomimoto S, Kunugi A, Suetake S, Baba A: Altered psychomotor behaviors in mice lacking pituitary adenylate cyclase-activating polypeptide (PACAP). Proc Natl Acad Sci USA 2001;98:13355-13360.

30 Norrholm SD, Das M, Legradi G: Behavioral effects of local microinfusion of pituitary adenylate cyclase activating polypeptide (PA$\mathrm{CAP}$ ) into the paraventricular nucleus of the hypothalamus (PVN). Regul Pept 2005;128: 33-41.

-31 Li Q, Holmes A, Ma L, Van de Kar LD, Garcia F, Murphy DL: Medial hypothalamic 5-hydroxytryptamine (5-HT) la receptors regulate neuroendocrine responses to stress and exploratory locomotor activity: application of recombinant adenovirus containing 5-HTla sequences. J Neurosci 2004;24: 10868-10877.

32 Swanson LW: Cerebral hemisphere regulation of motivated behavior. Brain Res 2000; 886:113-164.

33 Aizawa H, Sato Y, Maekawa M, Fujisawa H, Hirata T, Yuasa S: Development of the amygdalohypothalamic projection in the mouse embryonic forebrain. Anat Embryol (Berl) 2004;208:249-264

- 34 Kandalaft LE, Zudaire E, Portal-Nunez S, Cuttitta F, Jakowlew SB: Differentially expressed nucleolar transforming growth factor-beta1 target (DENTT) exhibits an inhibitory role on tumorigenesis. Carcinogenesis 2008;29:1282-1289.

- 35 Pham Y, Tu Y, Wu T, Allen TJ, Calkin AC, Watson AM, Li J, Jandeleit-Dahm KA, Toh BH, Cao Z, Cooper ME, Chai Z: Cell division autoantigen 1 plays a profibrotic role by modulating downstream signalling of TGF-beta in a murine diabetic model of atherosclerosis. Diabetologia 2010;53:170179.

36 Tu Y, Wu W, Wu T, Cao Z, Wilkins R, Toh $\mathrm{BH}$, Cooper ME, Chai Z: Antiproliferative autoantigen CDA1 transcriptionally up-regulates p21(Waf1/Cip1) by activating p53 and MEK/ERK1/2 MAPK pathways. J Biol Chem 2007;282:11722-11731. 